\title{
PREVALENCE OF GASTROINTESTINAL HELMINTH INFECTIONS IN INDIGENOUS CHICKENS OF SELECTED AREAS OF BARISAL DISTRICT, BANGLADESH
}

\author{
M. N. Alam ${ }^{1}$, M. Mostofa ${ }^{1}$, M. A. H. N. A. Khan ${ }^{2}$, M. A. Alim ${ }^{3}$, A. K. M. A. Rahman ${ }^{4}$ and A. A. Trisha ${ }^{1}$
}

${ }^{1}$ Department of Pharmacology, ${ }^{2}$ Department of Pathology, ${ }^{3}$ Department of Parasitology, ${ }^{4}$ Department of Medicine, Faculty of Veterinary Science, Bangladesh Agricultural University, Mymensingh-2202, Bangladesh

\begin{abstract}
The prevalence of gastrointestinal helminth infections and the gross pathological lesions produced by them were studied from February 2012 to January 2013 in the Department of Pharmacology of Bangladesh Agricultural University, Mymensingh. In this study, a total of 320 indigenous chickens aged ranging from 2 to 4 months were examined to identify the different types of gastrointestinal helminth infections in indigenous chickens. During routine examination, six species of helminth parasites were recorded, of which five species of nematodes such as Ascaridia galli, Heterakis gallinarum, Capillaria spp, Acuaria hamulosa and Dispharynx spiralis; and one species was cestode called Raillietina tetragona. The highest prevalence was observed for Ascaridia galli (41.56\%) followed in descending order by Raillietina tetragona (19.68\%), Heterakis gallinarum (15.62\%), Acuaria hamulosa (8.75\%), Capillaria spp. (4.68\%) and Disopharinx spiralis (1.56\%). The gross pathological lesions were observed in case of Acuaria hamulosa and Heterakis gallinarum infection. In case of Acuaria hamulosa infection keratinization of gizzard mucosa and cross section of adult Acuaria hamulosa were seen along with marked infiltration of neutrophils. The results of this study suggest that both nematodes and cestodes are highly prevalent in indigenous chickens in the studied area.
\end{abstract}

Key words: Prevalence, gastrointestinal helminthes, pathology, indigenous chickens

\section{INTRODUCTION}

Poultry rearing is one of the most appropriate income generating activities for rural women especially for landless and marginal farmers. The production of backyard poultry under Semi scavenging system is found suitable to the villagers as additional source of income and nutrient supplement (Latif, 2001). Backyard poultry is popular among rural people. However, the poultry production is hindered by many problems among which infectious diseases are most important (Ojok, 1993). In fact the indigenous chickens of Bangladesh are parasitized by various parasites (Sarkar, 1976). Very few studies have been undertaken so far to determine the prevalence of gastrosintestinal helminth infection in indigenous chickens in Bangladesh (Rabbi et al., 2006; Ferdushy et al., 2014). No such studies have been done in Barisal region. This paper describes the prevalence of gastrointestinal helminths infection in backyard poultry in Barisal district of Bangladesh.

\section{MATERIALS AND METHODS}

This study was conducted in the Department of Pharmacology, Department of Parasitology and Department of Pathology, Bangladesh Agricultural University, Mymensingh and Field Disease Investigation Laboratory (FDIL), Barisal. A systemic necropsy was performed, identify the classes of parasites, anatomic location in hosts and determineing the prevalence of gastrointestinal helminth infections in chickens of four selected Upazila of Barisal district.

\section{Study area and period}

The study area comprises four Upazila of Barisal district named as Barisal Sadar, Babugong, Bakergong and Banaripara. The altitude of the area is about 2 meters $(6 \mathrm{ft})$ from sea level. The survey was conducted from February, 2012 to January, 2013.

\section{Study population}

The study population comprises local deshi chickens (Gallus gallus domesticus). The chickens are kept in a free-range system where they are confined during night and free ranging during day time.

*Corresponding e-mail address: mostofa57@yahoo.com

Copyright $@ 2014$ Bangladesh Society for Veterinary Medicine

All rights reserved 0301/2014 


\section{N. Alam and others}

The feed is supplemented in the noon. The remaining time of the day the chickens scavenge in the surrounding area of the house, where they pick up feed like insects, arthropods, earthworms, different larvae, grasses, leaves, various grains, household wastes etc. The chickens of 2- 4 months of age were collected without any reference to sex.

\section{Sample size and sampling procedure}

The sample size was calculated by using the formula $n=Z^{2} P Q / L^{2}$ (Thrusfield, 1995), where $n=$ sample size, $\mathrm{P}=$ expected prevalence in the flock/ population, $\mathrm{Q}=1-\mathrm{P}$, and $\mathrm{L}=$ required precision, that is the largest acceptable differences between the true and the estimated prevalence. The exact prevalence of the helminth infections in that particular area was not known; so to maximize the sample size it was supposed that the expected prevalence was 50\%, precision was 5\%, and the confidence level was set to be $95 \%$. All the birds were purchased from the owners through a middle man, who was instructed to buy only the healthy birds within the selected area by adopting a simple random sampling method. The middleman was further instructed not to buy more than 2 (two) chickens from any of the sampled household. Four to eight chickens were purchased at a time and the same day the birds were transported to FDIL, Barishal where post-mortem examination was performed.

\section{Parasitological examination}

All the chickens were sacrificed by cervical dislocation and the birds was examined according to Permin and Hansen (1998) and all pathological lesions were recorded. To identify the gastrointestinal helminth, the whole digestive tract was removed carefully and subdivided into esophagus, crop, proventiculus, gizzard, intestine, caeca, and cloaca. All sections were opened longitudinally with a pair of scissors. The serosal surface of the proventiculus was examined carefully for the presence of embedded Tetramer spp. The keratinized layer of the gizzard was removed for detecting the presence of Acuaria hamulosa. After opening the intestine, the mucosa was scrapped and the proventicular glands was squeezed with the help of the forceps and washed under running tap water over a 90 nanometer aperture test sieve for recovering the smaller helminthes. All the larger helminthes was picked up from the sieve with forceps and the residual contents was examined under a microscope and all the parasites was collected and transferred to $70 \%$ alcohol. All the helminth was counted individually, placed in sample collection tube and shift to Department of Parasitology, Bangladesh Agricultural University, Mymensingh for identification. All the helminths were examined under light microscope and were identified on the basis of helminthological keys described by Soulsby (1982).

\section{Statistical analysis}

The prevalence of gastrointestinal helminth infections in local free-range chickens were calculated as a percentage of the host population that was infected with a specific parasite at a point of time (Thrusfield, 1995).

\section{RESULTS AND DISCUSSION}

The present study revealed that out of 320 indigenous chickens 294 (91.88\%; 95\% Confidence Interval (CI): 88.32-94.62) were infected by one or more species of helminth parasites (Table 1). Similar to our findings, Ferdushy et al. (2014) reported 84.6\% (95\% CI: 77.9-90.0) gastrointestinal helminth infection Narsingdi district in Bangladesh. However, Rabbi et al. (2006) reported relatively higher prevalence (100\%) of gastrointestinal helminth infection in indigenous chickens in Mymensingh district. The results of Rabbi et al. (2006) were based on a non-random sample of 80 indigenous chicken's viscera. The smaller size of the sample and non-randomness is responsible for the higher prevalence of gastrointestinal helminths other than probable regional variation. Mekibib et al. (2014) also reported similar prevalence (88.5\%; 95\% CI: 81.5-93.6) of gastrointestinal helminth infections in scavenging chickens from Ethiopia. The range of reported prevalence of gastrointestinal helminth infections from other parts of the world varied from 59.0-100\% (Wakelin, 1964; Romanenko et al., 1985; Guclu, 1994). But the disparity in between the result of the present and earlier works in other countries might be due to the variation among the geographical location of the research area, method of detection and sample size.

The species-wise prevalence of gastrointestinal helminth infection is shown in Table 2. The prevalence of Ascaridia galli was highest (41.56\%) followed by Raillitina tetragona (19.68\%), Heterakis gallinarum (15.62\%), Acuaria hamulosa (8.75\%), Capillaria spp (4.68\%) and Dispharynx spiralis (1.56\%). Rabbi et al. (2006) detected three species of nematodes (Ascaridia galli $87.50 \%$, Heterakis gallinarum $80 \%$ and Capillaria annulata 
Prevalence of gastrointestinal helminth infections in indigenous chickens

5\%), two species of cestode (Raillitina tetragona 100\% and Amoebotaenia sphenoides 40\%) and one species of trematode (Catatropis verrucosa 16.25\%) from indigenous chickens in Mymensingh. On the other hand, Ferdushi et al. (2014) found only two species of nematodes (A. galli and H. gallinarum) and one species of cestode (Raillitina spp).

Table 1. Parasites recovered from the gastrointestinal tract of indigenous chickens of Barisal District

\begin{tabular}{lll}
\hline Class of parasites & Nomenclature/ References & Location \\
\hline & Ascaridia galli (Schrank, 1788) & Small intestine \\
& Heterakis gallinarum (Schrank, 1788) & Caecum \\
Nematode & Capillaria spp (Molin, 1858) & Small intestine \\
& Acuaria hamulosa (Diesing, 1851) & Gizzard \\
& Dispharynx spiralis (Molin, 1858) & Proventiculus \\
Trematode & None & - \\
Cestode & Raillietina tetragona (Molin, 1858) & Small intestine \\
\hline
\end{tabular}

Table 2. Species wise prevalence of gastrointestinal helminths infections in indigenous chickens of Barisal district

\begin{tabular}{lllll}
\hline Class of parasites & Name of parasites & Positive $(\mathrm{n}=320)$ & Prevalence & 95\% Confidence interval \\
& & & & \\
\hline \multirow{2}{*}{ Nematoda } & Ascaridia galli & 133 & 41.56 & $36.11-47.18$ \\
& Heterakis gallinarum & 50 & 15.62 & $11.83-20.08$ \\
& Capillaria spp & 15 & 4.68 & $2.64-7.61$ \\
& Acuaria hamulosa & 28 & 8.75 & $5.89-12.39$ \\
\multirow{2}{*}{ Cestoda } & Dispharynx spiralis & 5 & 1.56 & $0.50-3.61$ \\
& Raillitena tetragona & 63 & 19.68 & $15.47-24.47$ \\
& Overall & 294 & $91.88 \%$ & $88.32-94.62$ \\
\hline
\end{tabular}




\section{N. Alam and others}

Table 3. Seasonal prevalence of gastrointestinal parasites in indigenous chickens

\begin{tabular}{llll}
\hline \multirow{2}{*}{ Spp. of parasite } & \multicolumn{3}{c}{ Seasonal Prevalence } \\
\cline { 2 - 4 } & Winter & Summer & Rainy \\
\hline A.galli & $31.57 \%$ & $39.68 \%$ & $45 \%$ \\
R. tetragona & $21.05 \%$ & $38.09 \%$ & $20 \%$ \\
H. gallinarum & $26.31 \%$ & $14.28 \%$ & $30 \%$ \\
Capillaria spp & $3.5 \%$ & $9.5 \%$ & $3.5 \%$ \\
A. hamulosa & $4 . \%$ & $4.7 \%$ & $5 \%$ \\
Dispharynx spiralis & $4 \%$ & $1.58 \%$ & - \\
\hline
\end{tabular}
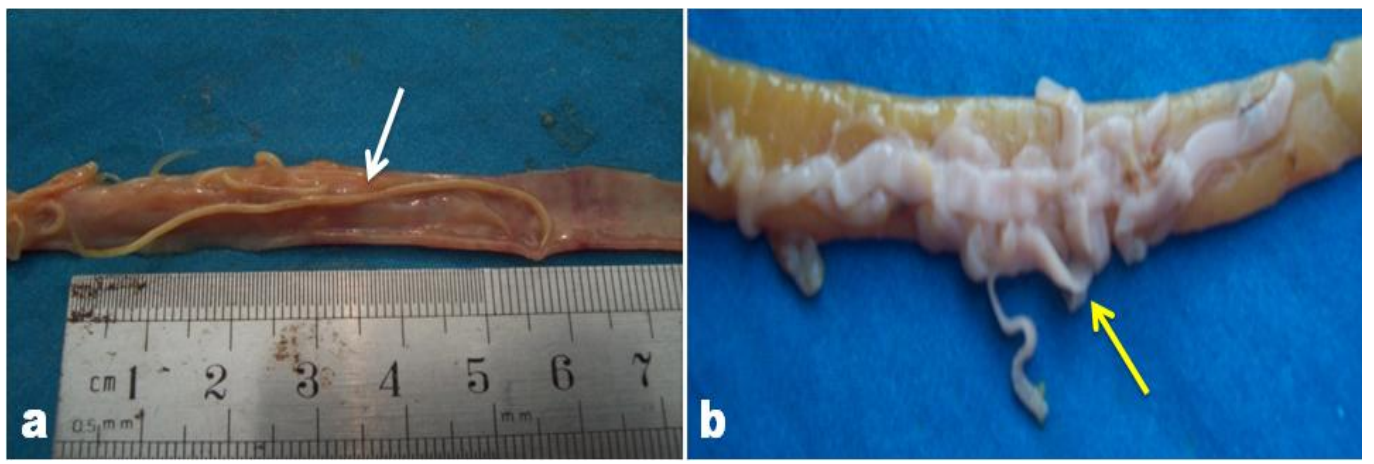

Fig. 1. Ascaridia galli (a) in small intestine of indigenous chickens (white arrow) showed mild hemorrhagic lesion in the intestinal mucosa. Commonly occurring tapeworm Raillitena tetragona (b, yellow arrow) revealed in the intestine following necropsy of an apparently healthy chickens.
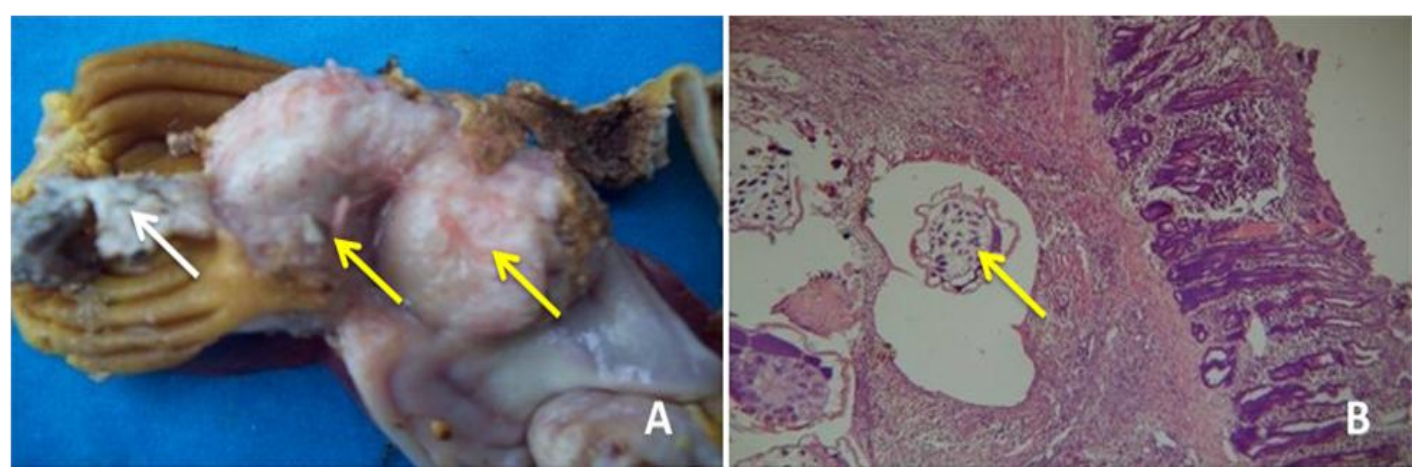

Fig. 2. Acuaria hamulosa (yellow arrow, A) in the gizzard of chickens producing keratinization of proventicular (A, white arrow) wall with marked thickening of gizzard. Cross section of adult Acuaria hamulosa was seen in the mucosa of gizzard (yellow arrow, B) along with marked infiltration of neutrophil and thickening of the musculature $(\mathrm{H} \& \mathrm{E}$, 10x). 
So, both nematodes and cestodes are common in indigenous chickens as it is evident from our and the other two studies. It is evident that nematodes are present. The paratenic host of A. galli and H. gallinarum is earth worm which is very common in Barisal district. It is also a favourite feed item for poultry. In case of $R$. tetragona, the ant of the genera Tetramorium, Pheidole and house fly Musca domestica act as intermediate host which are also available in our country, especially in the rural areas. Indigenous chickens are very fond of scavenging various insects from the nature. Easy access to these paratenic and intermediate hosts of A. galli and H. gallinarum may be responsible for the high prevalence of these parasites in this area. Relatively higher prevalence of A. galli (45\%), H. gallinarum (30\%) and A. hamulosa (5\%) were recorded in rainy season followed by summer and winter season (Table 3). However, higher prevalence of $R$. tetragona infection was observed in summer season. The prevalence of Dispharynx spiralis infection was noted only in summer (1.58\%) and winter season (4\%). Similar findings were also reported by Mukaratirwa et al. (2010).

Villagers rarely deworm their chickens as we have also observed that more than $90 \%$ chickens are infected with gastrointestinal helminths. Such a high burden will not only decrease the production potentials of the highly valuable indigenous chicken but will also cause mortality rendering serious economic loss to poor farmers.

So, regular dowering at three months interval with appropriate anthelmintics is recommended against both nematodes and cestodes.

\section{ACKNOWLEDGEMENTS}

The authors are grateful to National Agricultural technology project, Department of Livestock services, Govt. of Bangladesh for providing financial support to carry out the present research work as a part of PhD Program. Authors are also grateful to Dr. Abdul Jabbar Sikdar, Principal scientific officer, FDIL, Barisal for his cooperation during sample collection.

\section{REFERENCES}

1. Ferdushy T, Hasan MT and Kadir AKM (2014). Cross sectional epidemiological invesigation on the prevalence of gastrointestinal helminths in free range chickens in Narsingdi district, Bangladesh. Journal of Parasitic Disease DOI:10.1007/s12639-014-0585-5.

2. Mekibib B, Dejene H and Sheferaw D (2014). Gastrontestinal helminthes of scavenging chickens in outskirts of Hawassa, Southern Ethiopia. Global Veterinaria 12 (4): 557-561.

3. Guclu F (1994). Helminth fauna of fowls, Turkeys, ducks, and geese in the Ankara area. Doa-Turk- VeterinarlikVc-Hyavncilik-Dorgisi 18: 79-86.

4. Latif MA (2001). Microcredits and Savings of Rural Household of Bangladesh. The Bangladesh Development Studies 27: 51-71.

5. Mukaratirwa $S$ and Khumalo MP (2010). Prevalence of helminth parasites in free- range chickens from selected rural communities in Kwazulu- Natal province of South Africa. Journal of South African Veterinary Association 81: 2 .

6. Ojok L (1993). Disease as important factor affecting increased poultry production in Uganda. Der TropenlandwirZeiischrift fur die landwiirtschaft in din Trapen and Subtrapen 94: 37-44.

7. Permin A and Hansen JW (1998). Epidemiology Diagnosis and control of poultry parasites. Food and Agricultural organization of the United nations, Rome.

8. Rabbi AKMA, Islam A, Majumder S, Anisuzzaman and Rahman MH (2006). Gastrointestinal helminths infection in different types of poultry. Bangladesh Journal of Veterinary Medicine 4 (1): 13-18.

9. Romanenko PT, Troenko YAIA and Kuzyakin AV (1985). Age variation in helminth infection on chicken farm and factors farm in the Roostov region. Nahrung 29: 304-310.

10. Sarker AJ (1976). The prevalence of avian diseases in Bangladesh Agricultural University farm. Bangladesh Veterinary journal 10: 61-66.

11. Soulsby EJL (1982). Helminth Arthropods and Protozoa of Domesticated Animals. $7^{\text {th }}$ edn, Bailliere Tindal and Cassell Ltd. London.

12. Thursfield M (1995). Veterinary Epidemiology. $2^{\text {nd }}$ edn, Blackwell science, USA, p. 39-41.

13. Wakelin D (1964). A survey of the intestinal helminth parasites in British domestic fowls. Journal of Helminthology 38: 191-200. 